\title{
Mechanical integrity of thin inorganic coatings on polymer substrates under quasi-static, thermal and fatigue loadings
}

\author{
Y. Leterrier* * A. Mottet, N. Bouquet, D. Gilliéron, P. Dumont, A. Pinyol, L. Lalande, J.H. Waller, J.-A.E. Månson \\ Laboratoire de Technologie des Composites et Polymères (LTC), Ecole Polytechnique Fédérale de Lausanne (EPFL), CH-1015 Lausanne, Switzerland
}

\section{A R T I C L E I N F O}

Available online 12 June 2010

\section{Keywords:}

Residual stress

Fragmentation

Cohesive properties

Adhesive properties

Fatigue

\begin{abstract}
A B S T R A C T
The interplay between residual stress state, cohesive and adhesive properties of coatings on substrates is reviewed in this article. Attention is paid to thin inorganic coatings on polymers, characterized by a very high hygro-thermo-mechanical contrast between the brittle and stiff coating and the compliant and soft substrate. An approach to determine the intrinsic, thermal and hygroscopic contributions to the coating residual stress is detailed. The critical strain for coating failure, coating toughness and coating/substrate interface shear strength are derived from the analysis of progressive coating cracking under strain. Electrofragmentation and electro-fatigue tests in situ in a microscope are described. These methods enable reproducing the thermo-mechanical loads present during processing and service life, hence identifying and modeling the critical conditions for failure. Several case studies relevant to food and pharmaceutical packaging, flexible electronics and thin film photovoltaic devices are discussed to illustrate the benefits and limits of the present methods and models.
\end{abstract}

(C) 2010 Elsevier B.V. All rights reserved.

\section{Introduction}

Flexible and rollable electronics based on polymer substrates coated with stacks of inorganic films are developed at an unprecedented pace for a vast range of applications [1-4]. This paper reviews recent work on the mechanical integrity of such multilayer structures, which should not distort, crack and delaminate during processing and during service life. These materials are characterized by a very high hygro-thermo-mechanical contrast between the brittle and stiff coatings and the compliant and soft substrates. The resulting residual stress state of the coating, its cohesive and adhesive properties and its endurance under thermo-mechanical loading and fatigue are discussed in the following sections. Focus is on the development of experimental methods for accurate insight into the critical factors, which control the coating integrity. A number of coating/substrate combinations are presented as examples to illustrate the benefits and limits of the present methods and models.

\section{Intrinsic, thermal and hygroscopic stresses}

Prediction and control of residual stresses is crucial to achieve a high dimensional stability and avoid premature damage in multilayer structures. In the case of inorganic films deposited from a vapor phase

\footnotetext{
* Corresponding author.

E-mail address: yves.leterrier@epfl.ch (Y. Leterrier).
}

onto a polymer substrate, residual stresses include intrinsic, thermal and hygroscopic contributions [5-9]. The process dynamics of these stresses are sketched in Fig. 1 [10]. Intrinsic stresses are associated with deposition-induced disorder in the inorganic coating structure, and maybe tensile or compressive. Thermal stresses develop upon cooldown from process temperature, due to the mismatch in thermal expansion between material constituents and are generally compressive when using polymers as substrates. Hygroscopic stresses buildup upon exposure of the coated polymer processed in a vacuum environment to the ambient humidity, due to the mismatch in hygroscopic expansion between material constituents and are generally tensile. Additional stresses may develop in the coating during post-deposition processes due to further dimensional changes of the polymer substrate such as orientation relaxation and resulting shrinkage [11].

The individual components of the in-plane coating stress $\sigma_{\text {res }}=$ $\sigma_{i n}+\sigma_{t h}+\sigma_{h y}$ are identified using the protocol detailed in [9]. The intrinsic stress, $\sigma_{i n}$, is obtained in a first step, from the analysis of film curvature measured in vacuum and at the deposition temperature. The temperature-dependent thermal stress, $\sigma_{t h}$, and humiditydependent hygroscopic stress, $\sigma_{h y}$, are obtained from the change of curvature of the multilayer film subjected to iso-hygric temperature jumps and isothermal relative humidity jumps, respectively. In case of small displacements, $\sigma_{\text {res }}$ is related to the curvature changes of the coated film using Röll's model [12]:

$\sigma_{\text {res }}=-\frac{E_{s} h_{s}^{2}}{6\left(1-v_{s}\right) h_{c}}\left(1+\frac{h_{c}}{h_{s}}\left(4 \frac{E_{c}}{E_{s}}-1\right)\right) \cdot\left(\frac{1}{R_{2}}-\frac{1}{R_{1}}\right)$ 


\begin{tabular}{|c|c|}
\hline \multicolumn{2}{|c|}{ Nomenclature } \\
\hline $\mathrm{CD}$ & crack density \\
\hline$C D_{\text {sat }}$ & crack density at saturation \\
\hline \multicolumn{2}{|c|}{$\begin{array}{l}\mathrm{CHE}, \mathrm{CHE}_{c}, \mathrm{CHE}_{s} \text { coefficients of hygroscopic expansion, of coating, } \\
\text { of substrate }\end{array}$} \\
\hline \multicolumn{2}{|c|}{$\begin{array}{l}C T E, C T E_{c}, C T E_{s} \text { coefficients of thermal expansion, of coating, of } \\
\text { substrate }\end{array}$} \\
\hline$E_{c}, E_{s}$ & Young's moduli of coating, of substrate \\
\hline $\bar{E}_{c}, \bar{E}_{S}$ & plane strain moduli of coating, of substrate \\
\hline$g(\alpha ; \beta)$ & normalized energy release rate \\
\hline & coating toughness \\
\hline & steady-state energy release rate \\
\hline$h_{c}, h_{s}$ & thicknesses of coating, of substrate \\
\hline \multicolumn{2}{|c|}{ IFSS, IFSS* interfacial shear strength, intrinsic IFSS } \\
\hline$k$ & variable \\
\hline & number of cracks observed in a micrograph \\
\hline$R, R_{0}$ & electrical resistances of strained, of unstrained specimen \\
\hline$R_{1}, R_{2}$ & radii of curvature of substrate, of coated substrate \\
\hline & width of a micrograph \\
\hline$\alpha, \beta$ & Dundurs parameters \\
\hline$\chi$ & coating-to-substrate Young's modulus ratio \\
\hline & strain \\
\hline \multicolumn{2}{|c|}{$\varepsilon_{c r i t}, \operatorname{COS}$ coating crack onset strain } \\
\hline$\varepsilon_{\text {crit }}^{*}$ & intrinsic coating crack onset strain \\
\hline & coating residual strain \\
\hline$\nu_{c}, \nu_{s}$ & Poisson's ratio of coating, of substrate \\
\hline & coating-to-substrate thickness ratio \\
\hline & in-plane residual coating stress \\
\hline$\sigma_{i n}, \sigma_{t h}$ & $\begin{array}{l}\sigma_{\text {hy }} \text { intrinsic, thermal, hygroscopic contributions to } \\
\text { coating stress }\end{array}$ \\
\hline & tensile stress at yield of the substrate \\
\hline & shear stress at yield of the substrate \\
\hline
\end{tabular}

where $E_{s}$ and $E_{c}$ are the Young's moduli of substrate and coating respectively, $v_{s}$ is the substrate Poisson's ratio, $h_{s}$ and $h_{c}$ are the respective thicknesses, and $R_{1}$ and $R_{2}$ are the radii of curvature of the substrate and of the coated film. Compressive stresses are taken as negative by convention. The case of large displacements is treated in [13].

Fig. 2 shows the three contributions to the residual stress of $400 \mathrm{~nm}$ thick nitride and oxide coatings on a $125 \mu \mathrm{m}$ thick polyimide substrate (PI, Kapton VN, DuPont) at $22{ }^{\circ} \mathrm{C}$ and $50 \%$ relative humidity

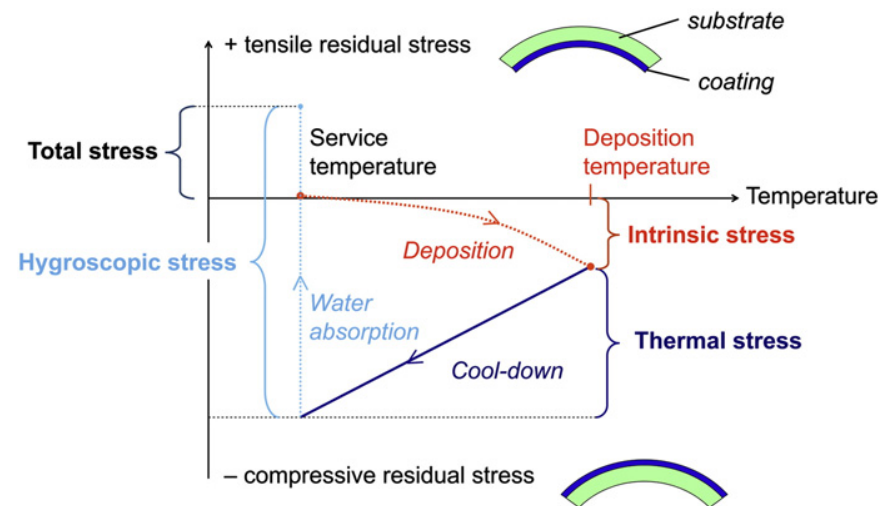

Fig. 1. (Adapted from [10]). Residual stress dynamics during vacuum deposition of coatings on polymer substrates.

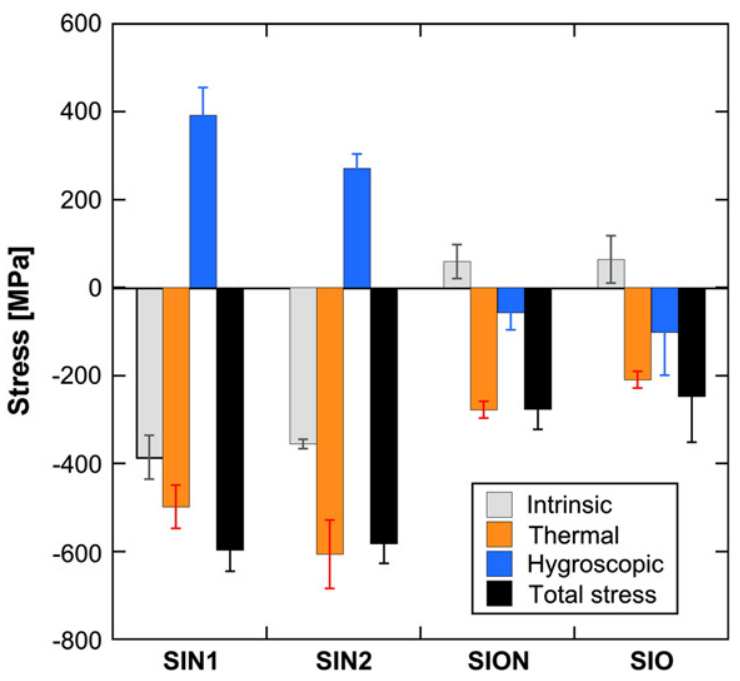

Fig. 2. Residual stress components in $400 \mathrm{~nm}$ thick SIN1, SIN2, SION and SIO coatings on a $125 \mu \mathrm{m}$ PI substrate at $22^{\circ} \mathrm{C}$ and $50 \% \mathrm{RH}$.

(RH). Four different compositions were produced using plasma enhanced chemical vapor deposition at $200{ }^{\circ} \mathrm{C}$, as detailed in Table 1 . Their stoichiometry was assessed using X-ray photoelectron spectroscopy. The Young's modulus of the SIN1 and SIN2 coatings, and of the SION and SIO coatings was taken from values obtained for $\mathrm{SiN}_{\mathrm{x}}$ coatings on a glass substrate and $\mathrm{SiO}_{2}$ coatings on a $\mathrm{Si}$ substrate using nanoindentation tests, respectively, with an accuracy of approximately $10 \%$. The Young's modulus of the substrate was found to be equal to $2.4 \mathrm{GPa}$ from tensile testing, and its Poisson's ratio was assumed to be 0.3 . The coefficients of thermal and hygroscopic expansion (CTE and CHE) of PI given the supplier were $36 \cdot 10^{-6} \mathrm{~K}^{-1}$ and $22 \cdot 10^{-6}(\% \mathrm{RH})^{-1}$, respectively. The coated foils were stored during several weeks in air at $22 \pm 2{ }^{\circ} \mathrm{C}$ and $50 \% \mathrm{RH}$. Rectangular samples of $55 \times 6 \mathrm{~mm}^{2}$ were cut from uncoated and coated foils. Isohygric thermal ramps up to $170{ }^{\circ} \mathrm{C}$ were carried out in a vacuum oven, i.e. at zero relative humidity. The samples were placed on two vertical razor blades to minimize contact friction with a distance of $40 \mathrm{~mm}$ between the blades and their radius of curvature was measured using a binocular lens (Olympus $\mathrm{SZH}$ ). The intrinsic stress was determined from a linear extrapolation to $200{ }^{\circ} \mathrm{C}$ of the radius of curvature measured between 100 and $170{ }^{\circ} \mathrm{C}$. The thermal stress at $22^{\circ} \mathrm{C}$ was also determined under vacuum. The hygroscopic stress at $22^{\circ} \mathrm{C}$ and $50 \% \mathrm{RH}$ was subsequently determined from the curvature of samples placed in an environmental chamber equipped with a RH generator (VTI RH-200) controlled by a hygrometer (Ebro RHT 200).

Residual stresses in the coating layers were systematically compressive, for all tested compositions. The intrinsic stress in the nitride coatings (SIN1 and SIN2) was compressive whereas it was slightly tensile for the oxygen rich SION and SIO coatings. The thermal stress was the largest component and was always compressive. It was a factor of two higher in absolute value for SIN1 and SIN2 compared to

Table 1

Young's modulus and coefficients of thermal and hygroscopic expansion of $400 \mathrm{~nm}$ thick silicon oxynitride coatings deposited on a PI substrate.

\begin{tabular}{lllll}
\hline Coating & Composition & $\begin{array}{l}\text { Young's modulus } \\
{[\mathrm{GPa}]}\end{array}$ & $\begin{array}{l}\mathrm{CTE} \\
{\left[10^{-6} \mathrm{~K}^{-1}\right]}\end{array}$ & $\begin{array}{l}\mathrm{CHE} \\
{\left[10^{-6}(\% \mathrm{RH})^{-1}\right]}\end{array}$ \\
\hline SIN1 & $\mathrm{SiO}_{0.05} \mathrm{~N}_{1.06}$ & $100 \pm 10$ & $2.0 \pm 0.2$ & $-57 \pm 10$ \\
SIN2 & $\mathrm{SiO}_{0.07} \mathrm{~N}_{1.00}$ & $100 \pm 10$ & $8.0 \pm 1.3$ & $-32 \pm 11$ \\
SION & $\mathrm{SiO}_{1.80} \mathrm{~N}_{0.05}$ & $66 \pm 7$ & $12 \pm 1.9$ & $39 \pm 34$ \\
SIO & $\mathrm{SiO}_{1.91} \mathrm{~N}_{0.04}$ & $66 \pm 7$ & $18 \pm 5.0$ & $53 \pm 55$
\end{tabular}


the other two coatings. The CTE of the coatings reported in Table 1 was calculated from the thermal stress, using the known CTE of PI. It was found to increase by an order of magnitude, from $2 \cdot 10^{-6} \mathrm{~K}^{-1}$ for SIN1 (comparable to the value for bulk $\mathrm{Si}_{3} \mathrm{~N}_{4}$ equal to $2.9 \cdot 10^{-6} \mathrm{~K}^{-1}$ ) to $23 \cdot 10^{-6} \mathrm{~K}^{-1}$ for SIO. These CTE data enable the thermal stress in the coatings on the PI substrate, and resulting curvature of the bilayer film to be calculated for any moisture free thermal path. Hygroscopic stresses were tensile for SIN1 and SIN2, and slightly compressive for the other two coatings. This result is consistent with the inert nature of silicon nitride and affinity of silicon oxide for moisture. The CHE of the coatings reported in Table 1 was also calculated from the hygroscopic stress and CHE of the PI substrate as given by the supplier. The error on CHE determination was rather large, and negative average $\mathrm{CHE}$ for the nitride layers were obtained. Values close to zero were expected [9], which may result from underestimated substrate CHE and limited model accuracy, in which the influence of coating/ substrate interface on moisture state was disregarded. This points out the challenge to investigate the influence of moisture on the behavior of polymer-based materials. It nevertheless appears that the CHE of the coatings increased with increasing oxygen concentration. Providing that these CHE data are available, the above analysis can be used to calculate the residual stress and resulting curvature of the bilayer film for any hygrothermal path.

\section{The fragmentation and electro-fragmentation test methods}

Numerous methods are available to determine the adhesion of coatings, including tape and pull-out tests, and indentation and scratch techniques [14]. The accuracy of these methods is however compromised by the presence of 'third-body interactions', such as indenter-coating friction in case of scratch and indentation tests, or adherent-coating traction in case of peel and pull-out tests. The fragmentation test method is free of third-body interactions. It enables quantifying the cohesive properties (which control cracking) and the adhesive properties (which control delamination) of coatings on high-elongation substrates [8]. The method has been used to analyze a broad range of coating/substrate combinations, including inorganic coatings on polymers [15-19], elastomers [20] and steel [21], and organic coatings on polymers [22-24]. In a fragmentation test, a coated substrate is loaded under uniaxial tension, and the damage state in the coating due to interfacial stress transfer from the substrate is analyzed as a function of strain. An alternative test to investigate interfacial adhesion is based on the analysis of buckling delamination upon compressive loading [25]. The fragmentation test is limited to high-elongation substrates (i.e., with a strain to failure several times higher than that of the coating). The fragmentation process reveals three damage stages depicted in Fig. 3 [26].

Stage I: crack onset and random cracking. Cracks initiate in the coating at defect sites and start propagating perpendicular to the loading direction at a critical strain, $\varepsilon_{\text {crit }}$ (also termed crack onset strain, COS). The interaction between cracks is negligible and the generation of new cracks is governed by the statistical distribution of defects within the coating.

Stage II: mid-point cracking. The size of coating fragments approaches the critical length for stress transfer. The generation of new cracks diminishes and transverse buckling is observed across fragments due to Poisson's ratio effects.

Stage III: delamination and saturation. No further cracks are generated in this stage and the density of cracks reaches a saturation value, $C D_{\text {sat }}$, related to the so-called critical stress transfer length [17]. Delamination becomes the dominant failure mechanism.

A number of theoretical approaches are available to analyze the fragmentation test data and obtain both cohesive and adhesive properties of coatings on substrates. The cohesive properties of the coating (critical strain, toughness, and Weibull modulus) are derived from fragmentation stage I $[16,17,27-30]$. The toughness can be
I

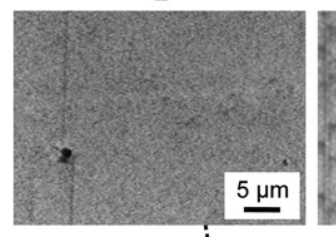

II
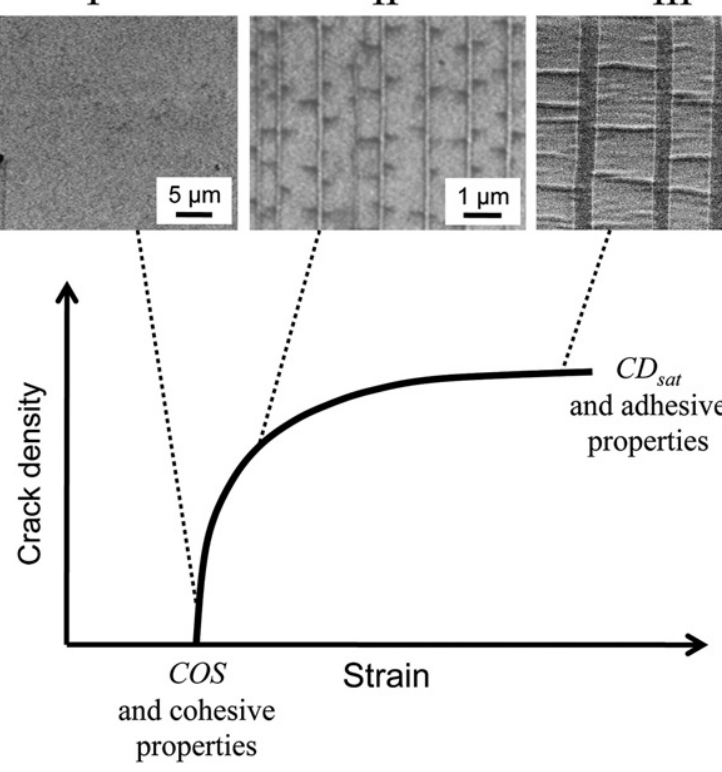

Fig. 3. (Adapted from [8]). The three stages of fragmentation of a coating under uniaxial loading: at a critical strain $\left(\varepsilon_{\text {crit }}\right)$ the sample starts cracking (stage I), at higher strain mid-point cracking begins and transverse fragment buckling initiates (stage II) and above a certain strain, no more cracks are formed and the crack density at saturation $\left(C D_{\text {sat }}\right)$ is reached (stage III). The micrographs show the fragmentation of a $20 \mathrm{~nm}$ thick $\mathrm{SiO}_{\mathrm{x}}$ coating on a $12 \mu \mathrm{m}$ thick PET substrate.

calculated assuming that it is equal to the energy release rate at critical strain [31,32]:

$G_{s s}=\frac{\pi}{2} h_{c} \bar{E}_{c} \varepsilon_{c r i t}^{2} g(\alpha ; \beta)$

where $\bar{E}_{c}=E_{c} /\left(1-\nu_{c}^{2}\right)$ is the plane strain modulus of the coating $\left(\nu_{c}\right.$ is the Poisson's ratio of the coating) and $g(\alpha, \beta)$ is a function of the Dundurs' parameters $\alpha$ and $\beta$, which describe the elastic mismatch of the layer/substrate system. In the case of plane strain problems $\alpha=$ $\left(\bar{E}_{c}-\bar{E}_{s}\right) /\left(\bar{E}_{c}+\bar{E}_{s}\right)$ where $\bar{E}_{s}=E_{s} /\left(1-\nu_{s}^{2}\right)$ is the plane strain modulus of the substrate. The function $g$ is primarily dependent on parameter $\alpha$, and in the present work we used $\beta=\alpha / 4$. The COS was also used to evaluate the critical radius, $R_{\text {crit }}$, at which cracks are initiated in bending mode [33]:

$R_{\text {crit }}=\left(\frac{h_{c}+h_{s}}{2 \varepsilon_{c r i t}}\right) \cdot\left(\frac{1+2 \eta+\chi \eta^{2}}{(1+\eta)(1+\chi \eta)}\right)$

Where $\eta=h_{c} / h_{s}$ and $\chi=E_{c} / E_{s}$.

The adhesive properties (interfacial shear strength) are derived from the analysis of the saturation stage III, and from the development of buckling damage in stage II [34]. A number of models were devised based on elastic [35-39], plastic [40-42] and elasto-plastic stress transfer analyses $[43,44]$. For yielded interfaces, which generally applies when fragmentation proceeds beyond the yield point of the substrate, IFSS was found to be proportional to $C D_{\text {sat }}$ :

IFSS $=1.337 h_{c} E_{c} \varepsilon_{\text {crit }} C D_{\text {sat }}$

Eq. (4) does not account for the possible statistical nature of coating strength (see e.g. [17]). In presence of residual stresses, the measured COS is in fact the linear combination of an intrinsic failure strain, $\varepsilon_{\text {crit }}^{*}$, and a residual strain, $\varepsilon_{\text {res }}\left(\varepsilon_{\text {crit }}=\varepsilon_{\text {crit }}^{*}-\varepsilon_{\text {res }}\right)$. The IFSS 
Table 2

Elastic, cohesive and adhesive properties of coatings on polymer substrates.

\begin{tabular}{|c|c|c|c|c|c|c|c|c|c|c|c|c|c|c|}
\hline \multirow{2}{*}{$\begin{array}{l}\text { Coating/ } \\
\text { substrate } \\
\text { structure }\end{array}$} & \multirow{2}{*}{$\begin{array}{l}\text { Temperature } \\
{\left[{ }^{\circ} \mathrm{C}\right]}\end{array}$} & \multicolumn{2}{|l|}{ Substrate } & \multicolumn{3}{|l|}{ Coating } & \multicolumn{2}{|c|}{ Elastic contrast functions } & \multicolumn{3}{|c|}{ Cohesive properties } & \multicolumn{3}{|c|}{ Adhesive properties } \\
\hline & & $\begin{array}{l}\text { Modulus } \\
E_{s}[\mathrm{GPa}]\end{array}$ & $\begin{array}{l}\text { Poisson's } \\
\text { ratio } v_{s}\end{array}$ & $\begin{array}{l}\text { Modulus } \\
E_{c}[\mathrm{GPa}]\end{array}$ & $\begin{array}{l}\text { Poisson's } \\
\text { ratio } v_{c}\end{array}$ & $\begin{array}{l}\text { Residual } \\
\text { stress } \\
\text { [MPa] }\end{array}$ & $\begin{array}{l}\text { Dundurs } \\
\text { parameter } \alpha\end{array}$ & Function $g$ & $\begin{array}{l}\text { Critical } \\
\text { strain } \\
\varepsilon_{\text {crit }}[\%]\end{array}$ & $\begin{array}{l}\text { Critical } \\
\text { radius }^{a} \\
{[\mathrm{~mm}]}\end{array}$ & $\begin{array}{l}\text { Toughness } \\
G_{c}\left[\mathrm{~J} / \mathrm{m}^{2}\right]\end{array}$ & $\begin{array}{l}C D_{\text {sat }} \\
{\left[\mathrm{mm}^{-1}\right]}\end{array}$ & $\begin{array}{l}\text { IFSS } \\
{[\mathrm{MPa}]}\end{array}$ & $\begin{array}{l}\text { IFSS* }^{*} \\
{[\mathrm{MPa}]}\end{array}$ \\
\hline OC/PET & 23 & 5.0 & 0.4 & 6 & 0.4 & - & 0.091 & 1.3 & 3.5 & 2.9 & 44.4 & 28 & 27.0 & - \\
\hline TCO/PEN & 23 & 6.6 & 0.37 & $119 \pm 5$ & 0.2 & -195 & 0.884 & 4.9 & 1.55 & 6.3 & 16.7 & 154 & 30.4 & 28.2 \\
\hline TCO/PEN & 150 & 1.6 & 0.45 & $119 \pm 5$ & 0.2 & -44 & 0.968 & 11.6 & 1.20 & 7.5 & 24.1 & 84 & 12.8 & 12.6 \\
\hline $\mathrm{SIO} / \mathrm{PI}$ & 23 & 2.4 & 0.3 & $66 \pm 7$ & 0.2 & -247 & 0.926 & 6.8 & 1.07 & 8.6 & 30.9 & 184 & 69.5 & 53.2 \\
\hline SIN1/PI & 23 & 2.4 & 0.3 & $100 \pm 10$ & 0.2 & -597 & 0.951 & 9.0 & 0.97 & 9.1 & 50.9 & 260 & 135 & 79.4 \\
\hline
\end{tabular}

a $200 \mu \mathrm{m}$ thick substrate.

obtained from Eq. (4) is, therefore, an apparent strength, which combines an intrinsic strength, IFSS*, and a residual stress term [8]:

$I F S S=I F S S^{*}-0.894 h_{c} C D_{\text {sat }} \sigma_{\text {res }}$

The factor $0.894 h_{c} C D_{\text {sat }}$ results from the yielding condition. The fragmentation test method is illustrated with four coated substrates cases, summarized in Table 2 . The first was a $75 \mu \mathrm{m}$ thick polyethylene terephthalate (PET, Melinex 506, DuPont) film coated with a $3.5 \mu \mathrm{m}$ thick organic coating $(\mathrm{OC})$. The modulus of the $\mathrm{OC}$ was measured from dynamic mechanical analysis of free-standing films. The second was a $50 \mu \mathrm{m}$ thick polyethylene naphthalate (PEN, Teonex, DTF) film coated with a $80 \mathrm{~nm}$ thick transparent conducting oxide (TCO) coating. The modulus of the TCO coating was calculated from the moduli of uncoated and coated substrates, using tensile test measurements and the classical laminate theory. A high-temperature polyester substrate (Arylite, Ferrania Imaging Technologies) was used for this purpose. The substrate thickness was very small $(12 \mu \mathrm{m})$ to maximize the influence of the coating on the measured coated substrate modulus. The glass transition temperature of the substrate was also high enough $\left(330^{\circ} \mathrm{C}\right)$ to prevent any modification of the substrate during coating deposition, which would have compromised the modulus calculation. The reported value (119 GPa) compares with the value obtained using nanoindentation on glass (112 GPa). The third and fourth were the SIN1/PI and SIO/PI films detailed in the previous section (Table 1). Such films are common in food packaging and flexible electronic devices. The Poisson's ratio of the coatings was estimated. The Young's modulus of the substrates was obtained from tensile tests, and their Poisson's ratio was estimated or taken from literature. The elastic function $g$ was calculated using the data from [31]. Fragmentation tests were carried out using rectangular film specimens (typical gauge dimensions $5 \mathrm{~mm} \times 20 \mathrm{~mm}$ ) and a miniature tensile stage (Linkam TST350) mounted under an optical microscope (Olympus BX60). This setup enabled analyzing coatings of thickness down to $50 \mathrm{~nm}$, below which a scanning electron microscope becomes necessary [45]. The crack density (CD) of the coatings was calculated from the average of the number of cracks, $N_{i}$, counted on $k$ micrographs of width $W$, at increasing strain levels $\varepsilon$, as $\mathrm{CD}=(1+\varepsilon) \sum_{i=1}^{k} N_{i} / k W$. The factor $(1+\varepsilon)$ corrected for crack opening to a first approximation.

Fig. 4 shows the progressive tensile damage in the OC and TCO coatings on the polymer substrates under strain. Both coatings were intact before loading. Initial cracks were detected around $4 \%$ and $2 \%$ strain (Fig. 4a, c) for the OC and TCO coatings, respectively. Upon further straining the crack density increased rapidly until saturation,
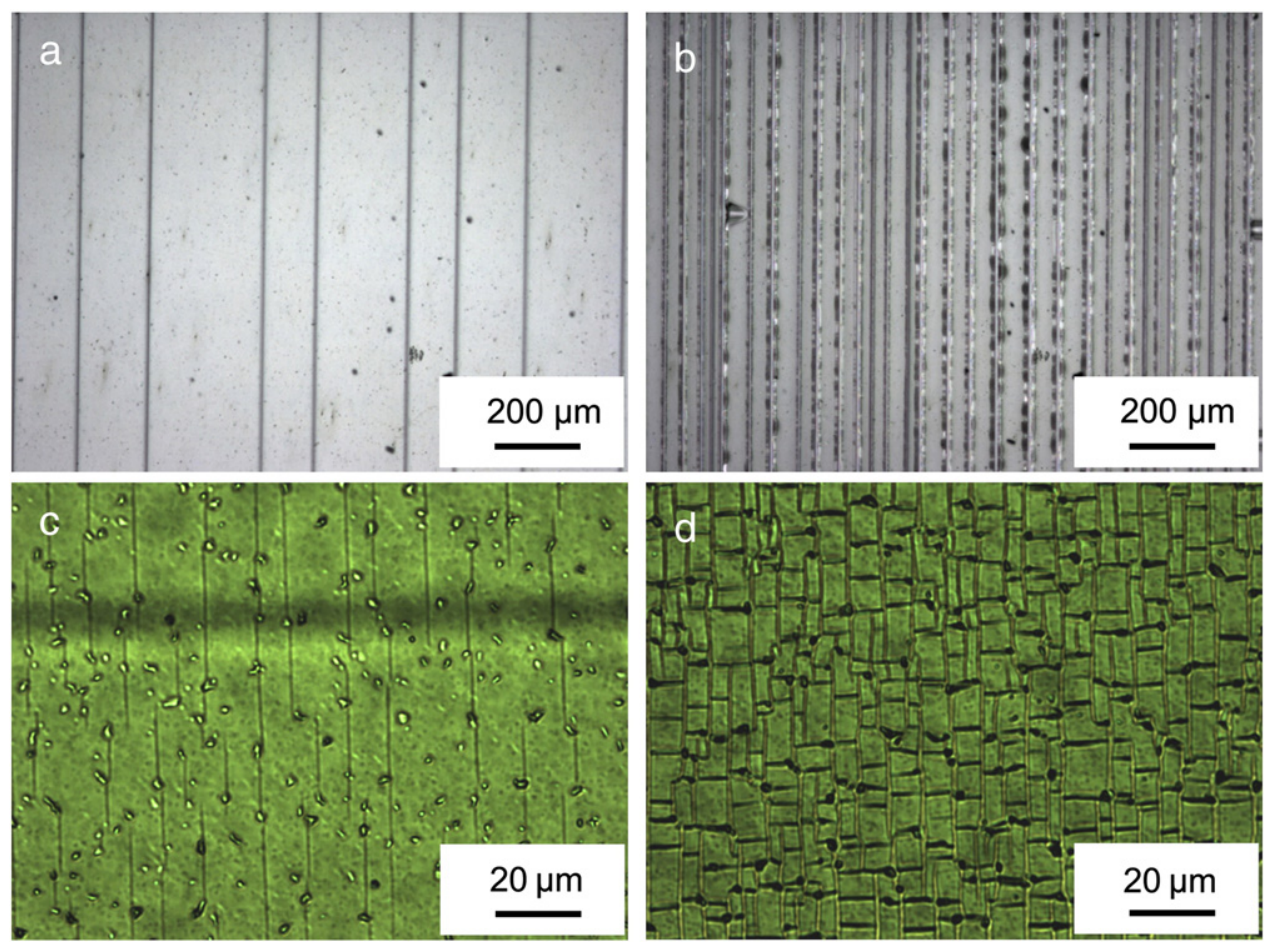

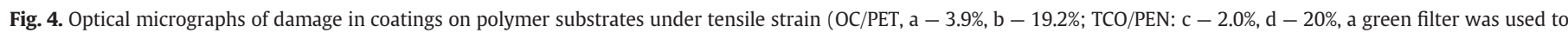
emphasize contrast) 
with evidence of buckling delamination at the edges of coating fragments (Fig. 4b, d). The fragmentation process for the four coatings is depicted in Fig. 5. The COS and calculated toughness (Eq. (2)) and the crack density at saturation and calculated IFSS (Eq. (4)) are reported in Table 2 . The coating toughness data were comparable with values for bulk materials (e.g., SIN1 [46]), at the exception of the silicon oxide coating (SIO) whose toughness was a factor of at least three times higher than fused silica [47]. The IFSS was found to vary from $27 \mathrm{MPa}$ for the OC coating to $135 \mathrm{MPa}$ for the SIN1 coating, thus reflecting the major differences in interfacial interactions promoted by the different coating processes. Accounting for the compressive residual stress leads to IFSS* values lower than the IFSS, in the range from 30 to $80 \mathrm{MPa}$ for the inorganic coatings. These values may be compared with the shear strength at yield of the polymer substrates, $\tau_{Y}$, estimated from their yield stress, $\sigma_{Y}$, using Von Mises equivalence $\left(\tau_{Y}=\sigma_{Y} / \sqrt{3}\right)[48]$. The yield stress of the PI substrate was equal to $155 \mathrm{MPa}$. The corresponding shear stress was equal to $89 \mathrm{MPa}$, which is higher than the IFSS*. This means that the interface will fail without strain hardening taking place (i.e., delamination will occur at strain levels below the yield strain of the substrate, see e.g. [49]), and that surface treatment of the substrate might be useful to further improve the adhesion.

The critical radius was also calculated from the COS (Eq. (3)). For comparative purposes, the same value of $200 \mu \mathrm{m}$ for the substrate thickness was used, rather than the actual value (the COS is independent of substrate thickness beyond several 10 times coating thickness [50]). Values below $1 \mathrm{~cm}$ were obtained, which provides a design limit for conformal and rollable devices. It will however be shown in a further section that this might only be true for short-term loading, and that a greater safety margin (i.e., a higher limit for the admissible radius of curvature) is likely to be required to ensure longterm stability under fatigue loading.

Further insight into coating damage development was obtained with the development of an electro-fragmentation test. Special clamps were designed to enable electrical resistance measurements and avoid contact artefacts resulting from coating failure in the clamps. The method was initially applied to conducting coatings, for which a correlation between crack initiation and resistance increase was established [51-54]. It was modified to enable analyzing nonconducting coatings using an additional conducting probe layer. A

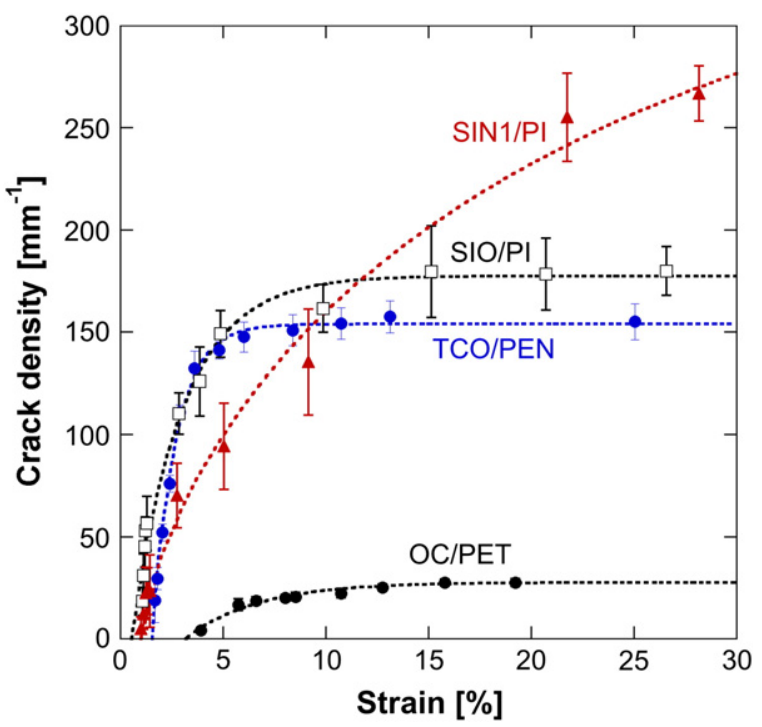

Fig. 5. Crack density vs. strain of a $3.5 \mu \mathrm{m}$ thick organic coating on a PET substrate (OC/PET), a $100 \mathrm{~nm}$ thick transparent conducting oxide film on a PEN substrate (TCO/PEN), a $400 \mathrm{~nm}$ thick $\mathrm{SiO}_{\mathrm{x}}$ coating on a PI substrate (SIO/PI) and a $400 \mathrm{~nm}$ thick $\mathrm{SiN}_{\mathrm{x}}$ coating on a PI substrate (SIN1/PI) under uniaxial loading. careful selection of this layer was carried out to avoid further artefacts such as changing the residual stress in the coating. The optimal probe layer was based on amorphous graphite (a-G) [55]. Fig. 6 compares the change of electrical resistance $\Delta R / R_{0}\left(\Delta R=R-R_{0}, R\right.$ and $R_{0}$ are the electrical resistances of the strained and unstrained specimen, respectively) of a $32 \mathrm{~nm}$ thick a-G layer on several nitride coatings with the crack density in the coatings. A clear correlation between the two damage events is evident. The initiation of cracks was associated with a $10 \%$ increase of resistance (significantly higher than the strain gage effect resulting from straining the conducting layer [54]). One notices that the COS decreases with increasing coating thickness as expected from fracture mechanics, which predicts that COS should scale with the inverse of square root of coating thickness (Eq. (2)). A model to correlate the tensile damage with the resistance increase within fragmentation stages I and II was moreover proposed in a recent work [56], enabling automatic detection of the overall damage development in ultrathin coatings on polymers. The electro-fragmentation method thus provides a powerful alternative to the rather impracticable optical detection of cracks in the case of experiments that may last few seconds (high strain rate), or several days or weeks (low strain rate and fatigue).

\section{Influence of temperature on adhesion}

Thin film deposition and further conversion processes are often carried out at elevated temperatures, resulting in thermal stresses

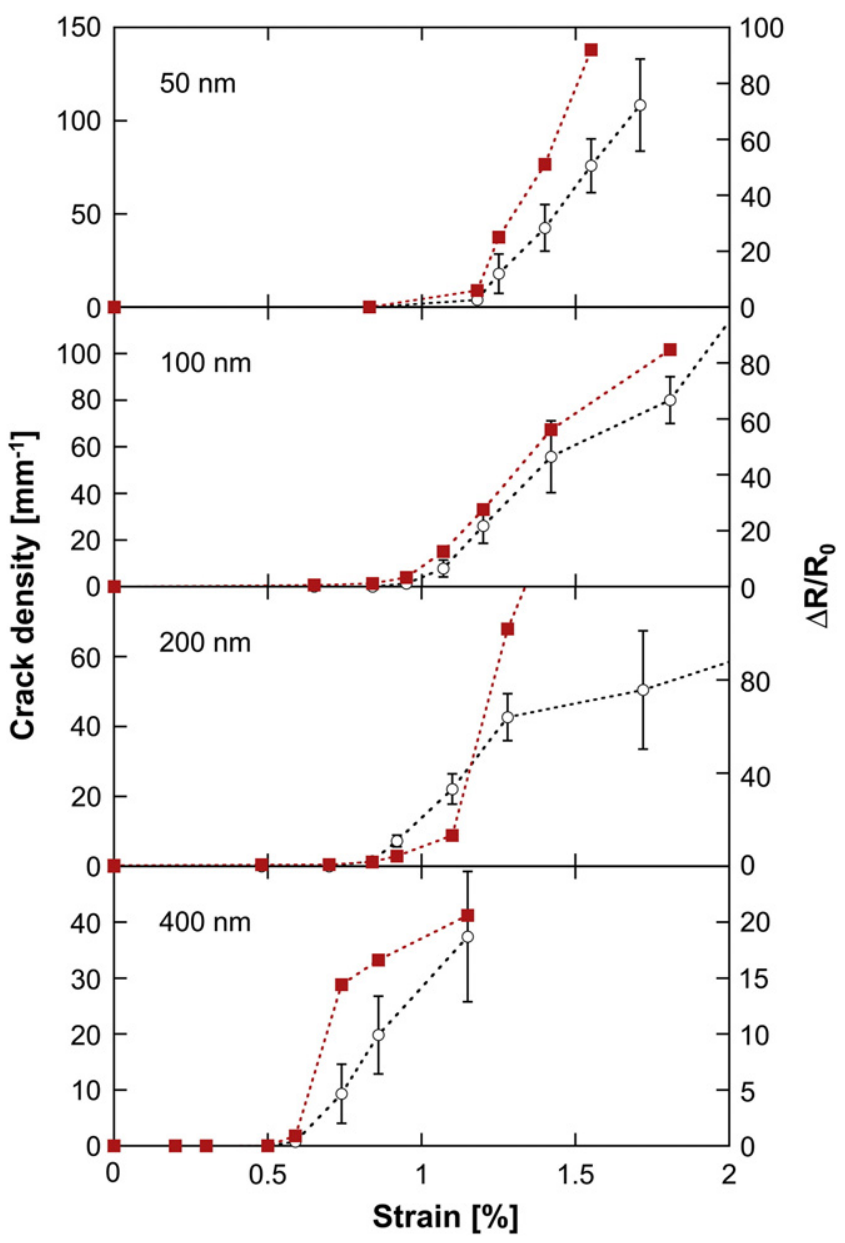

Fig. 6. (Adapted from [55]). Crack density (open symbols) and normalized change of electrical resistance (filled symbols) of $\mathrm{a}-\mathrm{G} / \mathrm{SiN}_{\mathrm{x}}$ coatings on PI vs strain. The thickness of the nitride coatings is indicated in the graphs. 
upon cool-down to room temperature as discussed in a previous section. Only few studies on this topic are available, where a correlation between IFSS and polymer properties, more specifically yield stress was established [17,57]. In the present work the fragmentation method was used to analyze the influence of thermal loads applied to coated components on the adhesion of the coating. The experimental setup was equipped with a temperature-controlled oven with a $\pm 0.1{ }^{\circ} \mathrm{C}$ stability up to $250{ }^{\circ} \mathrm{C}$, specially designed to fit in the microscope stage. Fig. 7 shows bright field optical micrographs of the TCO/PEN film at saturation, at $23^{\circ} \mathrm{C}$ and $150{ }^{\circ} \mathrm{C}$, where a marked reduction of $\mathrm{CD}$ at $150{ }^{\circ} \mathrm{C}$ compared to $23^{\circ} \mathrm{C}$ is evident. The COS was also reduced, from $1.55 \%$ at $23^{\circ} \mathrm{C}$ to $1.2 \%$ at $150{ }^{\circ} \mathrm{C}$, a result of tensile stresses controlled by the thermal expansion of PEN, as also to the increasing elastic contrast resulting from the softening of the polymer. The temperature-dependent IFSS and IFSS* were calculated using Eqs. (4) and (5), and the results are reported in Table 2. The residual stress at $150{ }^{\circ} \mathrm{C}$ was approximated by adding to the stress at $23{ }^{\circ} \mathrm{C}$ a thermal stress $\sigma_{t h}=E_{c}\left(C T E_{s}-C T E_{c}\right) \Delta T$, where $E_{c}=119 \mathrm{GPa}$, $C T E_{s}=20 \cdot 10^{-6} \mathrm{~K}^{-1}, C T E_{c}=10 \cdot 10^{-6} \mathrm{~K}^{-1}$, and $\Delta T=150-23$. The marked decrease of IFSS and IFSS* on temperature reflects the temperature dependence of the polymer substrate, rather than a degradation of the adhesion quality. In fact, at $150{ }^{\circ} \mathrm{C}$ the PEN substrate was considerably more compliant than at $23^{\circ} \mathrm{C}$, in contrast to the TCO coating whose modulus was assumed to be independent of temperature in the investigated range. The transfer of the substrate stress to the coating through interfacial shear (i.e., the adhesion), responsible for the coating failure observed in Fig. 7 was thus much less effective at higher temperature, and this was emphasized with the buildup of tensile thermal stresses. The consequence was a reduction of the $C D_{\text {sat }}$ of the TCO coating, and correlated decrease of IFSS and IFSS* The present analysis enables to evaluate the respective influence of fundamental interactions (which control IFSS*) and residual stresses on the practical adhesion of coatings.

\section{High cycle fatigue behavior of thin oxide films on polymer substrates}

The critical strain for coating cracking is usually determined using quasi-static loading $[21,49]$, which might not be representative of the actual fatigue loading present during operational life. High cycle fatigue (HCF) of thin films on polymer substrates has been studied in details in case of metallic films (especially $\mathrm{Cu}$ and $\mathrm{Al}$ ) [58-65], whose damage state was primarily related to the grain structure. Fatigue studies of oxide films are much fewer and limited to conducting materials (especially Sn-doped $\operatorname{In}_{2} \mathrm{O}_{3}$, ITO) since these enable probing damage through electrical resistance measurement [66,67]. The present study was motivated by initial observations of stable cracks in ITO films, which grew under fatigue loading at strain levels below the critical strain for unstable crack propagation under tensile loading $[68,69]$. The objective was to further investigate the HCF endurance of such films on a polymer substrate. Focus was put on a layered $\mathrm{Ag} / \mathrm{ITO}$ film found to be more robust than plain ITO films [67]. The approach was to correlate a macroscopic damage state variable (e.g., electrical resistance) to the actual damage at microscopic scale, using a combination of electrical measurements and microscopy analyses.

The material was a $50 \mu \mathrm{m}$ thick polyethylene terephthalate substrate (PET, DT401, DTF) coated with a $136 \mathrm{~nm}$ thick Ag/ITO multilayer (ITO $30 \mathrm{~nm} / \mathrm{Ag} 8 \mathrm{~nm} / \mathrm{ITO} 60 \mathrm{~nm} / \mathrm{Ag} 8 \mathrm{~nm} / \mathrm{ITO} 30 \mathrm{~nm}$, ITOA). The sheet resistivity and COS of the ITOA film were $4 \Omega / \square$ and $1.15 \%$, respectively. The computer-controlled electro-fatigue apparatus was constituted of a steel frame with high-accuracy linear bearings and a linear variable differential transducer for strain control. The device was mounted under an optical microscope (Olympus BH-2). Rectangular samples (gauge dimensions $5 \mathrm{~mm} \times 40 \mathrm{~mm}$ ) were clamped under a small pre-strain $\left(5 \cdot 10^{-4}\right)$. A sinusoidal movement up to prescribed maximum strain was applied under displacement control to the sample using a stepper motor and an eccentric mechanism. Videoextensometry was used to measure sample strain with accuracy better than $10^{-3}$. It was verified that creep phenomena did not occur in the investigated strain range, which was well below the yield point of the polymer substrate. The device movement was stable over 500,000 cycles at frequencies up to $2 \mathrm{~Hz}$, i.e. during more than $70 \mathrm{~h}$. The device was also equipped with special clamps to enable electrical resistance measurements with a multimeter (Agilent 34410A). Extreme care was exercised to obtain a reliable electrical contact, which was achieved with a copper pin and a conductive colloidal silver paste and found to be stable over more than 100,000 cycles (variation in electrical resistance lower than $2 \%$ ). Tests were performed at $2 \mathrm{~Hz}$ at $23 \pm 1{ }^{\circ} \mathrm{C}$ and $62 \pm 3 \%$ relative humidity. Extension of the method to dielectric coatings is possible with a conductive probe layer [55], as shown in Fig. 6.

Fig. 8 shows the normalized change of electrical resistance during cycling loading between $5 \cdot 10^{-4}$ pre-strain and maximum strain (indicated as a fraction of $\operatorname{COS}$ in the figure) in logarithmic coordinates. The resistance correlated with the cyclic strain as can be seen during the first 15 cycles (at higher number of cycles the oscillations merge and form a thick curve in log-scale). The same correlation is evident in the inset, where six cycles to maximum strain of $0.92 \%$ are shown. At low maximum strain $(0.26 \%=23 \%$ of the COS $)$ the resistance increased by $1 \%$ due to strain gage effect, and relaxed to approximately $0.2 \%$ upon unloading to the small pre-strain. At this maximum strain level no damage could be detected up to 100,000 cycles. The same result was obtained at a maximum strain of $0.36 \%$ ( $31 \%$ of the COS). At intermediate maximum strain $(0.58 \%=50 \%$ of the $\operatorname{COS}$ ) the resistance increase during the first cycle reached $3 \%$, again due to strain gage effect. However, it increased progressively
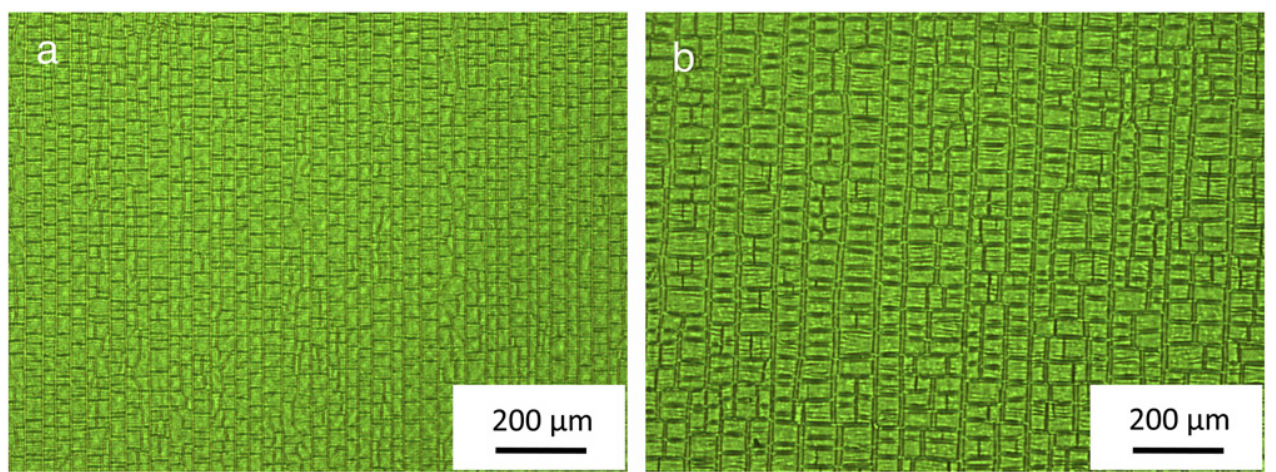

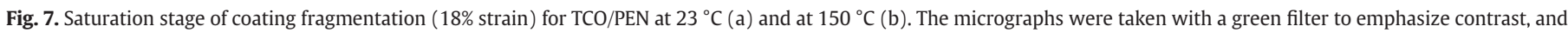
the loading direction was parallel to the scale bar in the micrographs. 


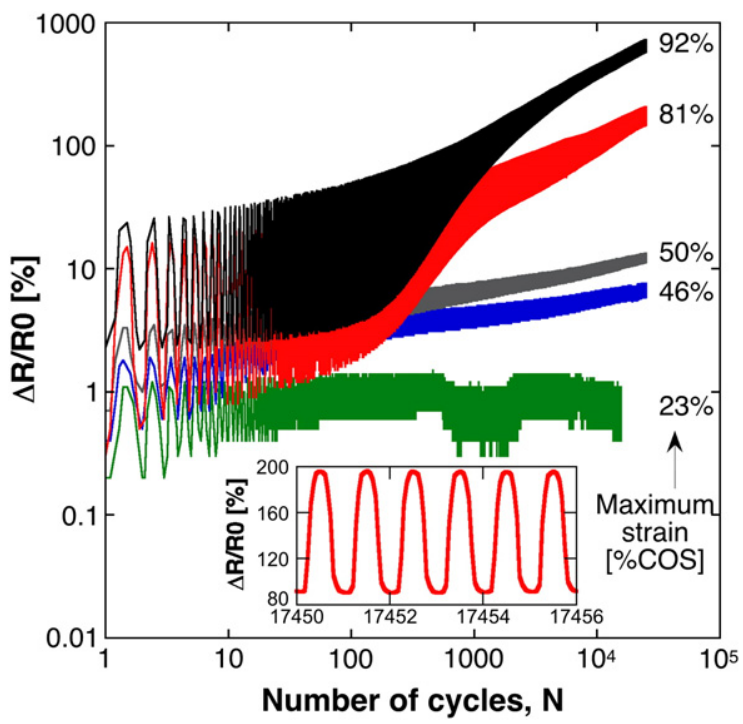

Fig. 8. Normalized change of electrical resistance of the ITOA coating on PET during cycling loading between $5 \cdot 10^{-4}$ pre-strain and maximum strain (indicated as a fraction of COS in the figure). The inset shows the normalized change of electrical resistance over six cycles to maximum strain of $0.92 \%$.

and reached $15 \%$ after 100,000 cycles where few tensile cracks were observed. Delaminated buckles around initial defects were also detected. The ratio between maximum and minimum resistance was approximately constant. At high maximum strain (above $0.9 \%=80 \%$ of the COS), the resistance increased by more than $10 \%$ during the first cycle, and by more than $500 \%$ after 10,000 cycles. Interestingly, the ratio between maximum and minimum resistance was very large in the early stages and, beyond approximately 100 cycles, it progressively decreased to the same value as for lower strain amplitude. At even larger maximum strain, beyond the COS, crack initiated and immediately propagated during the 1st cycle, and all cracks had propagated before the 10th cycle (data shown later in Fig. 10).

The damage state of the ITOA coating during cyclic loading to maximum strain of $0.92 \%$ ( $80 \%$ of the COS) is shown in Fig. 9a-c. Short tensile cracks, several $100 \mu \mathrm{m}$ in length, formed during the first cycle perpendicularly to the applied load, similarly to quasi-static tensile loading (see chapter 6 in [1]). These cracks propagated in a stable manner upon further cycling simultaneously to the formation of new cracks. Coating delamination was also noticed in the form of buckles around defect spots, with a preferential direction parallel to the applied load. These resulted from the transverse compressive stress controlled by the Poisson's ratio of the substrate [34]. Around 5,000 cycles the tensile cracks became unstable and propagated almost instantly to the edges of the sample. Beyond 100,000 cycles all cracks had reached the unstable propagation limit, and buckles had propagated in the vicinity of initial coating defects (Fig. 9d).

The succession of damage events is summarized in Fig. 10, where iso-resistance levels are shown vs. number of cycles and maximum strain. The analysis of the data shown in Fig. 8 and the in-situ optical microscopy observations revealed that initiation of tensile cracks corresponded to $\Delta R / R_{0}=10 \%$, and that stable propagation occurred until $\Delta R / R_{0} \sim 300 \%$ after which catastrophic failure took place. Quite remarkably, the same power-law scaling was found between maximum strain and critical number of cycles for both initiation and propagation of tensile cracks. The fatigue strength exponent was found to be equal to -0.06 , slightly lower than that of $\mathrm{Cu}$ films [62] and twice as high compared to that of thin silicon films [70].

The present scaling follows the modified Basquin law for non-zero mean stress [71], which enables predicting damage events in ITOA coatings upon fatigue loading to any strain levels. For instance, at maximum strain equal to $70 \%$ of the COS, cracks will initiate after ca. 70 cycles and catastrophic failure will occur after ca. 800,000 cycles. The existence of a threshold strain (detected for zirconia films [72] but
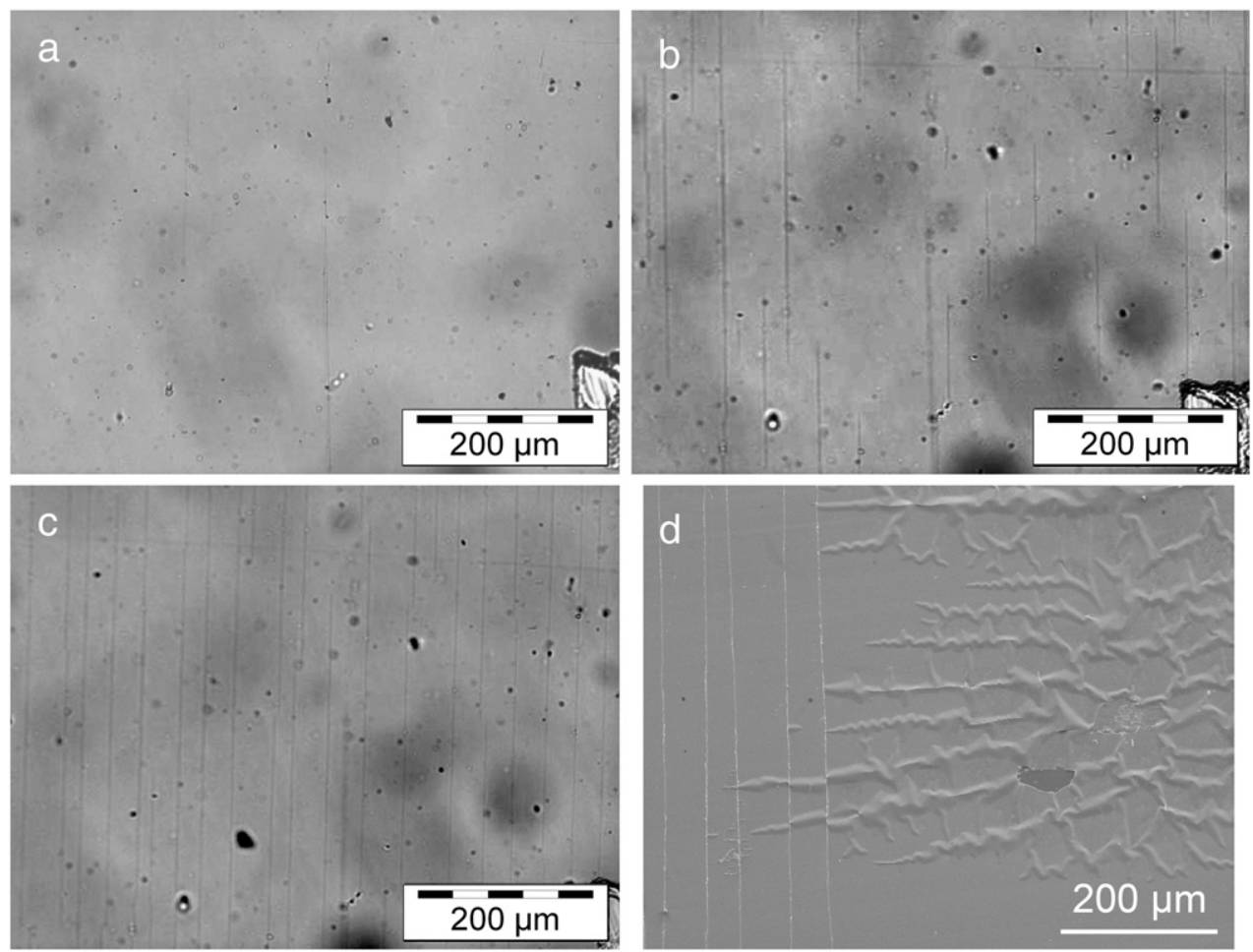

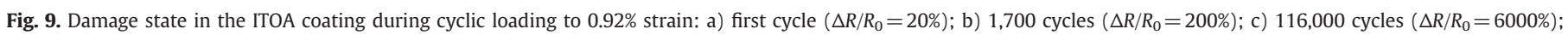
d) 450,000 cycles $\left(\Delta R / R_{0}>10,000 \%\right)$ 


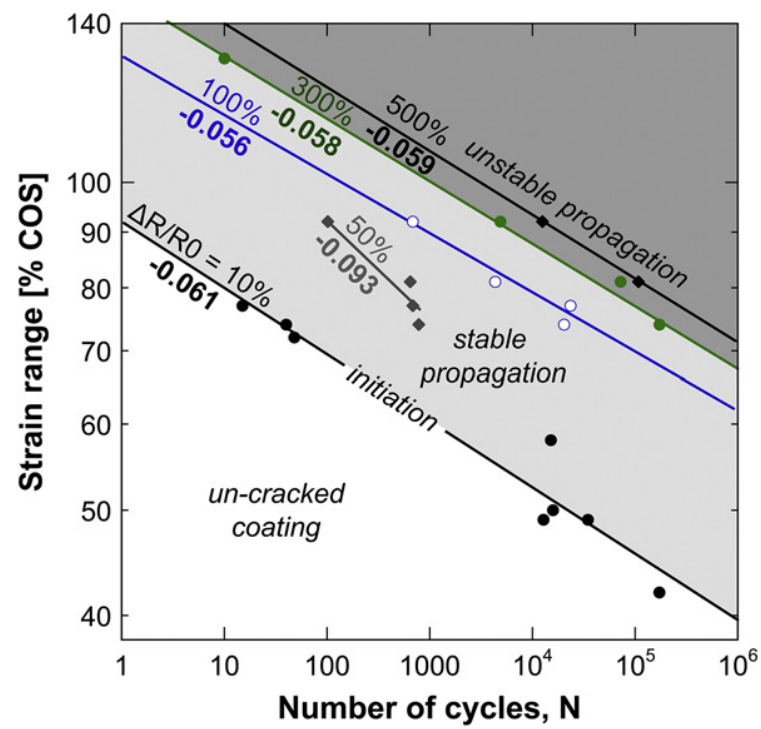

Fig. 10. Fatigue damage map of the ITOA coating. The lines are power law fits to the experimental data for selected resistance increase levels (indicated in percentages in the figure together with the fatigue strength exponents).

absent for bulk metals and Al films [61]) was not investigated. It would be lower than $40 \%$ of the COS and would correspond to an endurance limit well beyond $10^{5}$ cycles for the ITOA coating.

\section{Conclusions}

Approaches to determine the critical thermo-mechanical factors, which control the integrity of thin and brittle inorganic coatings on high-elongation polymer substrates were reviewed. A protocol was devised for detailed insight into residual coating stresses. Temperaturecontrolled fragmentation tests equipped for electrical resistance measurement and fatigue tests, both in situ in a microscope were developed for accurate analysis of coating cohesive and adhesive properties. The benefits of these in-situ methods include the direct observation of failure events and the ability to reproduce environmental conditions present during process operations, or during operational life. Several coating/substrate film systems were selected, with attention paid to the interplay between residual stress state, cohesive and adhesive properties of the coatings. The analysis of the experimental data leads to the following conclusions.

Residual stresses in nitride and oxide coatings on a PI substrate at $22{ }^{\circ} \mathrm{C}$ and $50 \% \mathrm{RH}$ were found to be compressive and close to $-600 \mathrm{MPa}$ and $-250 \mathrm{MPa}$, respectively. This difference was found to result from the different combinations of intrinsic, thermal and hygroscopic stresses. The analysis of these stress components enabled the CTE and the CHE of the coatings to be determined, however with a large error for the CHE. The critical strain for cracking of inorganic coatings was found to be in the range from $0.5 \%$ to $1.5 \%$ depending on coating composition and thickness. The corresponding toughness was of the order of several $10 \mathrm{~J} / \mathrm{m}^{2}$ and often comparable to the values for the bulk materials. IFSS was found to be of the order of several $10 \mathrm{MPa}$, with large differences between coated substrate systems. Knowledge of the residual stress state enabled obtaining intrinsic IFSS data, found to be lower than the shear stress at yield of the polymer substrate for conducting oxide coating on PEN and a silicon oxide and silicon nitride coatings on PI. The analysis of the HCF behavior of a transparent electrode coating revealed that sub-critical cracks grow under fatigue loading at relatively low strain levels below the COS (approx. 60\% COS) until catastrophic failure. The same power-law scaling was found between maximum strain and critical number of cycles for both initiation and propagation of tensile cracks, with a fatigue strength exponent equal to -0.06 .

\section{Acknowledgements}

The authors are grateful to the EU-funded Flexidis project (IST004354), to the Swiss Commission for Technology and Innovation and to Essilor International and VHF Technologies for funding this work and supplying film samples. They would like to acknowledge Philips Research Laboratories and Applied Materials for fruitful partnerships and the EPFL center for electron microscopy for technical support. Janis Andersons from the University of Latvia and Piet Bouten from Philips Research Laboratories are acknowledged for active collaboration and for the nanoindentation tests.

\section{References}

[1] G.P. Crawford, Flexible Flat Panel Displays, John Wiley \& Sons, Chichester, England, 2005.

[2] J. Lewis, Mater. Today 9 (2006) 38.

[3] M.C. Choi, Y. Kim, C.S. Ha, Prog. Polym. Sci. 33 (2008) 581.

[4] M. Pagliaro, R. Ciriminna, G. Palmisano, ChemsusChem 1 (2008) 880.

[5] M. Ohring, The Materials Science of Thin Films, Academic Press, New-York, 1992.

[6] S. Tamulevicius, Vacuum 51 (1998) 127.

[7] F. Spaepen, Acta Mater. 48 (2000) 31.

[8] Y. Leterrier, Prog. Mater. Sci. 48 (2003) 1.

[9] P. Dumont, G. Tornare, Y. Leterrier, J.-A.E. Månson, Thin Solid Films 515 (2007) 7437.

[10] Y. Leterrier, A. Pinyol, P. Dumont, D. Gillieron, V. Mewani, J.-A.E. Månson, J Andersons, P. Bouten, P. Timmermans, 2008 SID International Symposium, Digest of Technical Papers, 39, 2008, p. 310.

[11] Y. Leterrier, Y. Wyser, J.A.E. Månson, J. Adhes. Sci. Technol. 15 (2001) 841

[12] K. Röll, J. Appl. Phys. 47 (1976) 3224.

[13] C.B. Masters, N.J. Salamon, Int. J. Eng. Sci. 31 (1993) 915.

[14] K.L. Mittal, Adhesion Measurement of Films and Coatings, VSP, Utrecht, The Netherlands, 1995.

[15] P.H. Wojciechowski, M.S. Mendolia, J. Vac. Sci. Technol. A 7 (1989) 1282.

[16] Y. Leterrier, J. Andersons, Y. Pitton, J.-A.E. Månson, J. Polym. Sci. B: Polym. Phys. 35 (1997) 1463.

[17] Y. Leterrier, L. Boogh, J. Andersons, J.-A.E. Månson, J. Polym. Sci. B: Polym. Phys. 35 (1997) 1449.

[18] S. Ben Amor, G. Baud, M. Benmalek, H. Dunlop, R. Frier, M. Jacquet, J. Adhes. 65 (1998) 307.

[19] G. Rochat, Y. Leterrier, C.J.G. Plummer, J.-A.E. Månson, R. Szoszkiewicz, A.J. Kulik, P. Fayet, J. Appl. Phys. 95 (2004) 5429.

[20] S.L. Bazhenov, A.L. Volynskii, V.M. Alexandrov, N.F. Bakeev, J. Polym. Sci. B: Polym. Phys. 40 (2002) 10.

[21] J. Plojoux, Y. Leterrier, J.-A.E. Månson, F. Templier, Thin Solid Films 515 (2007) 6890

[22] J.A. Nairn, S.R. Kim, Eng. Fract. Mech. 42 (1992) 195.

[23] H.X. Tang, B. Foran, D.C. Martin, Polym. Eng. Sci. 41 (2001) 440.

[24] D.C. Martin, Prog. Org. Coat. 48 (2003) 332.

[25] A.A. Abdallah, D. Kozodaev, P.C.P. Bouten, J.M.J. den Toonder, U.S. Schubert, G. de With, Thin Solid Films 503 (2006) 167.

[26] D.R. Wheeler, H. Osaki, ACS Symp. Ser. 440 (1990) 500.

[27] C.Y. Hui, D. Shia and L.A. Berglund, 02.03.01, 59 (1999) 2037.

[28] S. Ochiai, S. Iwamoto, T. Nakamura, H. Okuda, ISIJ Int. 47 (2007) 458.

[29] J.A. Nairn, in: A. Kelly, C. Zweben (Eds.), Comprehensive Composite Materials, Vol. 2. Polymer-Matrix Composites, Chap. 12, Elsevier, Oxford, 2000, p. 403.

[30] S.R. Kim, J.A. Nairn, Eng. Fract. Mech. 65 (2000) 573.

[31] J.L. Beuth, Int. J. Solids Struct. 29 (1992) 1657.

[32] J. Andersons, J. Modniks, Y. Leterrier, G. Tornare, P. Dumont, J.-A.E. Månson, Theor Appl. Fract. Mech. 49 (2008) 151.

[33] H. Gleskova, S. Wagner, Z. Suo, Appl. Phys. Lett. 75 (1999) 3011.

[34] J. Andersons, S. Tarasovs, Y. Leterrier, Thin Solid Films 507 (2009) 2007.

[35] H.L. Cox, Br. J. Appl. Phys. 3 (1952) 72.

[36] Z. Hashin, S. Shtrikman, J. Mech. Phys. Solids 11 (1963) 127.

[37] J.A. Nairn, Mech. Mater. 12 (1992) 131.

[38] J.A. Nairn, Mech. Mater. 26 (1997) 63.

[39] D.-A. Mendels, Y. Leterrier, J.-A.E. Månson, J. Compos. Mater. 33 (1999) 1525.

[40] A. Kelly, W.R. Tyson, J. Mech. Phys. Sol. 13 (1965) 329.

[41] D.C. Agrawal, R. Raj, Acta Metall. 37 (1989) 1265.

[42] Y. Leterrier, Y. Wyser, J.-A.E. Månson, J. Hilborn, J. Adhes. 44 (1994) 213.

[43] M.R. Piggott, Load Bearing Fiber Composites - Reinforcement Processus, Pergamon, Elmsford, NY, 1980.

[44] A.P. McGuigan, G.A.D. Briggs, V. Burlakov, M. Yanaka, Y. Tsukahara, Thin Solid Films 424 (2003) 219.

[45] G. Rochat, Y. Leterrier, J.-A.E. Månson, P. Fayet, Thin Solid Films 437 (2003) 204.

[46] J.B. Wachtman, Mechanical Properties of Ceramics, John Wiley \& Sons, New-York, 1996.

[47] S.W. Freiman, in: D.R. Uhlmann, N.J. Kreidl (Eds.), Elasticity and Strength of Glasses, Glass Science and Technology, vol 5, Academic Press, New York, 1980.

[48] D.G. Howells, B.M. Henry, Y. Leterrier, J.A.E. Månson, J. Madocks, H.E. Assender, Surf. Coat. Technol. 202 (2008) 3529.

[49] J. Andersons, Y. Leterrier, G. Tornare, P. Dumont, J.A.E. Månson, Mech. Mater. 39 (2007) 834. 
[50] Y. Leterrier, A. Pinyol, D. Gilliéron, J.-A.E. Månson, P. Timmermans, P. Bouten, F. Templier, Eng. Fract. Mech. 77 (2010) 660.

[51] D.R. Cairns, R.P.W. II, D.K. Sparacin, S.M. Sachsman, D.C. Paine, G.P. Crawford, R.R Newton, Appl. Phys. Lett. 76 (2000) 1425.

[52] Z. Chen, B. Cotterell, W. Wang, Eng. Fract. Mech. 69 (2002) 597.

[53] E. Fortunato, P. Nunes, A. Marques, D. Costa, H. Aguas, I. Ferreira, M.E.V. da Costa M.H. Godinho, P.L. Almeida, J.P. Borges, R. Martins, Adv. Eng. Mater. 4 (2002) 610

[54] Y. Leterrier, L. Médico, F. Demarco, J.-A.E. Månson, M. Escola-Figuera, M. KharraziOlsson, U. Betz, F. Atamny, Thin Solid Films 460 (2004) 156.

[55] A. Pinyol, B. Meylan, D. Gilliéron, V. Mewani, Y. Leterrier, J.A.E. Månson, Thin Solid Films 507 (2009) 2007.

[56] Y. Leterrier, A. Pinyol, L. Rougier, J.H. Waller, J.-A.E. Månson, J. Appl. Phys. 106 (2009) 113508.

[57] M. Yanaka, Y. Kato, Y. Tsukahara, N. Takeda, Thin Solid Films 356 (1999) 337.

[58] O. Kraft, R. Schwaiger, P. Wellner, Mater. Sci. Eng. A 319-321 (2001) 919.

[59] E. Martynenko, W. Zhou, A. Chudnovsky, R.S. Li, L. Poglitsch, J. Electron. Packag. 124 (2002) 254

60] S.P. Lacour, D. Chan, S. Wagner, T. Li, Z.G. Suo, Appl. Phys. Lett. 88 (2006) 204103

[61] C. Eberl, R. Spolenak, O. Kraft, F. Kubat, W. Ruile, E. Arzt, J. Appl. Phys. 99 (2006) 113501.

[62] J.H. Park, J.H. An, Y.J. Kim, Y.H. Huh, H.J. Lee, Mat.-wiss. u. Werkstofftech. 39 (2008)
[63] X.J. Sun, C.C. Wang, J. Zhang, G. Liu, G.J. Zhang, X.D. Ding, G.P. Zhang, J. Sun, J. Phys. D Appl. Phys. 41 (2008) 6

[64] G.P.Zhang, K.H. Sun, B. Zhang, J. Gong, C. Sun, Z.G. Wang, Mater. Sci. Eng. A 483-484 (2008) 387.

[65] S. Eve, N. Huber, A. Last, O. Kraft, Thin Solid Films 517 (2009) 2702.

[66] D.R. Cairns, G.P. Crawford, Proc. IEEE 93 (2005) 1451.

[67] J. Lewis, S. Greco, B. Chalamala, E. Vick, D. Temple, Appl. Phys. Lett. 85 (2004) 3450.

[68] A. Pinyol, B. Meylan, D. Gilliéron, A. Mottet, V. Mewani, Y. Leterrier, J.-A.E. Månson, in: V. Buloviæ, S. Coe-Sullivan, I. Kymissis, J. Rogers, M. Shtein, T. Someya (Eds.), Large-Area Processing and Patterning for Active Optical and Electronic Devices (Mater. Res. Soc. Symp. Proc. Volume 1030E, Warrendale, PA, 2008), 2008, 1030-G03-12.

[69] J.S. Oh, Y.R. Cho, K.E. Cheon, M.A. Karim, S.J. Jung, Sol. State Phenom. 124-126 (2007) 411.

[70] C.L. Muhlstein, S.B. Brown, R.O. Ritchie, Sens. Actuat. A 94 (2001) 177.

[71] J. Morrow, in: J.A. Graham, Society of Automotive Engineers, Vol. AE-4 (Ed.), Fatigue Design Handbook, Section 3.2, Warrendale, PA, 1968

[72] M.J. Filiaggi, R.M. Pilliar, D. Abdulla, J. Biomed. Mater. Res. (Appl. Biomed.) 33 (1996) 239 